\title{
A CASE OF LONG TERM SURVIVAL IN WOMAN WITH METASTATIC BREAST CANCER TREATED WITH TRASTUZUMAB
}

\author{
Deyan Nikolov Davidov, \\ Department of Chemotherapy, UMHAT- Dr. G. Stranski, \\ Medical University, Pleven, Bulgaria
}

\section{SUMMARY:}

Intravenous Trastuzumab is an effective treatment for metastatic breast cancer after failure of first- line chemotherapy for patients with human epidermal growth factor 2 (HER-2) - positive receptor. The aim of this study is to present of case of long time survival woman with metastatic breast cancer. The case is a 55-years old female. She underwent left mastectomy with axillary lymphadenectomy for breast cancer. Histological examination showed invasive ductal carcinoma, grade III, estrogen and progesterone receptor- negative, HER2positive receptor status. Radiotherapy and six courses with antracyclines were performed as adjuvant chemotherapy. One year after the operation she was diagnosed to have lung metastases. Treatment was initiated with Trastuzumab $8 \mathrm{mg} / \mathrm{kg}$ for loading dose and $4 \mathrm{mg} / \mathrm{kg}$ maintenance dose every week. Treatment was continued for more than two years. Control computer tomography indicates stable disease. No adverse events were reported for twenty four months of Trastuzumab treatment. Treatment was stopped due to patients withdrawn. Overall survival was 31 months. This case indicate that long term Trastuzumab would be an optimal treatment for HER2- positive breast cancer patients.

Key words: Long term survival, Metastatic breast cancer, Trastuzumab

\section{INTRODUCTION}

Breast cancer represents a heterogeneous array of different disease subtypes that have unique molecular phenotypes and distinct clinical features (1). Despite advances in the treatment of early- stage breast cancer, approximately one third of patients will eventually develop metastatic breast cancer (MBC) (2). The prognosis of patients with $\mathrm{MBC}$ is poor, with a median survival time of 26 months (3). Recently, advances in understanding the biology of breast cancer have led to the classification of breast tumors based upon their molecular features and the advent of targeted therapies for the treatment of both early and metastatic cancer. Targeted agents and their promise of better patient outcomes with respect to safety, survival, and quality of life may change the clinical course for many MBC patients.

The human epidermal growth factor receptor (HER)2 gene is a member of a gene family that encodes for transmembrane receptor tyrosine kinases, including the epidermal growth factor receptor. Approximately 20\%-30\% of human breast tumors overexpress the HER-2 gene, and patients with HER-2-overexpressing tumors experience early progression and a poor prognosis in the metastatic setting $(4,5)$. Trastuzumab, a humanized monoclonal antibody directed against the extracellular domain of HER-2, has been developed for the treatment of HER-2- overexpressing breast cancers. In the pivotal phase III randomized trials in patients with $\mathrm{MBC}$, the application of trastuzumab after failure of first- line chemotherapy resulted in longer times to progression (TTP), higher response rates, and higher survival rates than with chemotherapy alone (6). However, HER- 2- positive MBC is an aggressive disease, and despite these advances, the majority of patients, treated with trastuzumab- based regimens progress within one year, with only very few patients experiencing prolonged remission (7).

The case report presented here describes a woman who underwent a mastectomy for invasive ductal carcinoma and subsequently received trastuzumab- containing chemotherapy as treatment for a metastatic lesions in the lung. She experienced a stable disease and has been receiving maintenance trastuzumab for twenty- four months.

\section{Case presentation}

In February 2001, an otherwise healthy 55 -year-old Caucasian woman, with no history of hormone therapy, smoking, drinking, or a family history of breast cancer, presented with a lump in the center of her left breast. The axillary and neck lymph nodes were not palpably enlarged. After breast biopsy, radiography of the chest and ultrasound of the abdomen, the patient underwent a radical left mastectomy. Pathologic examination of the resected specimens diagnosed HER2- positive (immunohistochemistry $3+$ ), hormone receptor- negative, grade III, invasive ductal carcinoma of the left breast with two positive axillary lymph nodes. The size of the primary 
tumor was $3,5 \times 4,5 \times 3 \mathrm{~cm}$. She was treated with adjuvant chemotherapy, six cycles of epirubicin, 5-fluorouracil and cyclophospfamide $(60 \mathrm{mg} / \mathrm{m} 2,600 \mathrm{mg} / \mathrm{m} 2$ and $600 \mathrm{mg} / \mathrm{m} 2$, respectively). On completion of chemotherapy, radiation therapy was administered to the left breast. In November 2003, after CT, the patient presented with a single metastatic lesion (diameter $2,5 \mathrm{~cm}$ ) in the at segment 7 of the right lung; no biopsy was carried out because patient was unwilling to undergo such a procedure. Trastuzumab (4 mg/ $\mathrm{kg}$ loading dose and $2 \mathrm{mg} / \mathrm{kg}$ maintenance dose weekly thereafter, with 21- days repetition) was started as first- line metastatic therapy in December 2004. Reevaluation of the lesion by radiography and $\mathrm{CT}$ followed regularly thereafter and showed a stable disease. The patient continued to receive maintenance Trastuzumab monotherapy $(6 \mathrm{mg} / \mathrm{kg}$ every three weeks) for 24 months, and she remains in stable disease. Throughout this period, the patient was in good health and led an active life without significant adverse effects. After two years treatment with Trastuzumab she decided to stop the treatment despite being informed about the possible chance of relapse after Trastuzumab withdrawal. She continues his treatment with observation only. The overall survival was 31 months after start the Trastuzumab treatment.

\section{DISCUSSION}

Clinical management of $\mathrm{MBC}$ remains a significant therapeutic challenge as oncologists balance improvements in overall survival with patients' quality of life. Despite more than 30 years of research, MBC remains essentially incurable, with a median survival time of approximately two years (8). The prognosis is poorer in patients with HER- 2positive MBC (4). Trastuzumab- based therapies have greatly improved the survival rates of these patients, with the largest benefits seen when treatment is continued at least until disease progression (9). However, if Trastuzumab is withdrawn, there is the possibility that disease may relapse. Preclinical data suggest that previously suppressed tumor growth resumes rapidly if Trastuzumab is withdrawn (10). Effective treatment of HER- 2- positive disease therefore seems to require prolonged attenuation of HER2 - activity, and it is difficult to define a time point beyond which Trastuzumab might not offer additional benefit. Furthermore, evidence in the literature supports the idea that continuing anticancer treatments as maintenance therapy in patients with stable disease may prolong the disease- free interval (11). There is an increasing number of case reports describing patients who experienced long- term remission from HER- 2- positive MBC while receiving Trastuzumab maintenance therapy $(12,13)$. The duration of remission in these cases ranges from four months to eight years, and in all cases, maintenance therapy was based on Trastuzumab.

One of these cases also illustrates the risk of withdrawing Trastuzumab treatment when the patient had experienced three years of full remission in the liver but relapsed in the central nervous system within two months of withdrawal of trastuzumab maintenance therapy (13). An important concern of many clinicians regarding long- term use of Trastuzumab is cardiac tolerability owing to the unexpected high incidence of cardiac events reported by the early pivotal trials, particularly when associated with anthracyclines. It is difficult to compare trials with different end points and eligibility criteria; however, the understanding of Trastuzumab related cardiac events has since improved, and the majority of these events are manageable and reversible. Extending Trastuzumab treatment does not appear to be associated with an increased risk of cardiac dysfunction. In studies of Trastuzumab treatment beyond progression, cardiac events appear to be relatively uncommon and mostly asymptomatic (14-16).

\section{CONCLUSION}

We suggest that a number of patients experience prolonged remission while receiving Trastuzumab maintenance therapy. We propose that the molecular profile of a tumor and its biological environment, as governed by the specific traits of a patient, will influence whether a patient achieves long- lasting remission on maintenance Trastuzumab therapy. Maybe the specific localization of breast cancer metastases may be a factor for long survival as many of the cases reported to date are mainly associated with liver metastases $(12,13)$. Why this might be contributory needs additional investigation.

\section{REFERENCES:}

1. Slamon DJ, Romond EH, Perez EA. Advances in adjuvant therapy for breast cancer. Clin Adv Hematol Oncol. 2006;4 (suppl 1): 4- 9. [PubMed]

2. Polychemotherapy for early breast cancer: An overview of the randomised trials. Early Breast Cancer Trialists' Collaborative Group. Lancet. 1998; 352: 930-942. [CrossRef] [PubMed]

3. Gennari A, Conte P, Rosso R,
Orlandini C, Bruzzi P. Survival of metastatic breast carcinoma patients over a 20-year period: A retrospective analysis based on individual patient data from six consecutive studies. Cancer. 2005 Oct 15;104(8):1742-1750. [PubMed]

4. Slamon DJ, Clark GM, Wong SG, Levin WJ, Ullrich A, McGuire WL. Human breast cancer: Correlation of relapse and survival with amplification of the HER-2/neu oncogene. Science 1987 Jan 9;235(4785):177-182. [CrossRef] [PubMed]

5. Press MF, Bernstein L, Thomas PA, Meisner LF, Zhou JY, Ma Y, et al. HER-2/ neu gene amplification characterized by fluorescence in situ hybridization: Poor prognosis in node negative breast carcinomas. J Clin Oncol. 1997 Aug;15(8):2894-2904. [PubMed] 
6. Slamon DJ, Leyland-Jones B, Shak S, Fuchs H, Paton V, Bajamonde A, et al. Use of chemotherapy plus a monoclonal antibody against HER-2 for metastatic breast cancer that overexpresses HER-2. N Engl J Med 2001 Mar;344(11):783-792. [CrossRef]] [PubMed]

7. Nahta R, Yu D, Hung MC, Hortobagyi GN, Esteva FJ., Mechanisms of disease: understanding resistance to HER2-targeted therapy in human breast cancer. Nat Clin Pract Oncol 2006 May;3(5):269-280. [CrossRef] [PubMed]

8. Bernard-Marty C, Cardoso F, Piccart MJ: Facts and controversies in systemic treatment of metastatic breast cancer. Oncologist 2004, 9(6):617-632. [CrossRef] [PubMed]

9. Marty M, Cognetti F, Maraninchi D, Snyder R, Mauriac L, Tubiana-Hulin $\mathrm{M}$, et al: Randomized phase II trial of the efficacy and safety of trastuzumab combined with docetaxel in patients with human epidermal growth factor receptor 2-positive metastatic breast cancer administered as first-line treatment: the M77001 study group. J Clin Oncol 2005 Jul 1;23(19):4265-4274. [CrossRef] [PubMed]
10. Pietras RJ, Pegram MD, Finn RS, Maneval DA, Slamon DJ: Remission of human breast cancer xenografts on therapy with humanized monoclonal antibody to HER-2 receptor and DNA-reactive drugs. Oncogene 1998 Oct 29;17(17):2235-2249. [CrossRef] [PubMed]

11. Falkson G, Gelman RS, Pandya KJ, Osborne CK, Tormey D, Cummings FJ, et al. Eastern Cooperative Oncology Group randomized trials of observation versus maintenance therapy for patients with metastatic breast cancer in complete remission following induction treatment. J Clin Oncol 1998 May;16(5):1669-1676. [PubMed]

12. Beda M, Basso U, Ghiotto C, Monfardini S: When should trastuzumab be stopped after achieving complete response in HER2-positive metastatic breast cancer patients? Tumori 2007, 93:491-492. [PubMed]

13. Масіб Escalante S, Rodriguez Lescure Б, Pons Sanz V, Marthnez Banaclocha N, Guillŭn Ponce C, Carrato Mena A. A patient with breast cancer with hepatic metastases and a complete response to herceptin as monotherapy. Clin Transl Oncol 2006 Oct;8(10):761-

\section{3. [PubMed]}

14. Tripathy D, Slamon DJ, Cobleigh M, Arnold A, Saleh M, Mortimer JE, et al: Safety of treatment of metastatic breast cancer with trastuzumab beyond disease progression. J Clin Oncol $2004 \mathrm{Mar}$ 15;22(6):1063-1070. [CrossRef] [PubMed]

15. Fountzilas G, Razis E, Tsavdaridis D, Karina M, Labropoulos S, Christodoulou C, et al: Continuation of trastuzumab beyond disease progression is feasible and safe in patients with metastatic breast cancer: a retrospective analysis of 80 cases by the Hellenic Cooperative Oncology Group. Clin Breast Cancer 2003 Jun;4(2):120-125. [CrossRef] [PubMed]

16. Von Minckwitz G, Zielinski C, Maarteense E, Vogel P, Schmidt M, Eidtmann H, et al: Capecitabine vs. capecitabine + trastuzumab in patients with HER2-positive metastatic breast cancer progressing during trastuzumab treatment: The TBP phase III study (GBG 26/BIG 3-05) (abstract). J Clin Oncol. (Meeting Abstracts) 2008 May;26(15 Suppl):1025.

\author{
Address for correspondence: \\ Dr. Deyan Nikolov Davidov, \\ Department of Chemotherapy, Oncological Center, Medical University, \\ 1 "St. Kliment Ohridsky" Str., 5000 Pleven, Bulgaria \\ Phone: +359/64/886 138, Fax: +359/64/831634 \\ E-mail: dean_davidov@abv.bg
}

